See Article page 59.

\section{Commentary: The mini-Bentall approach: Small and safe!}

\author{
Manfred Richter, MD, and Oliver J. Liakopoulos, MD
}

First described in 1968 by Hugh Bentall and Antony De Bono, ${ }^{1}$ the Bentall procedure is a well-established surgical technique for replacement of the aortic valve, aortic root, and ascending aorta with a composite graft. The Bentall procedure and its modifications represent an established approach to treating various pathologies of the aortic root, with excellent long-term results. Therefore, current guidelines of the European Society of Cardiology recommend aortic root replacement with a composite graft when a valve-sparing technique is not feasible. ${ }^{2}$

Over the past 2 decades, the introduction of minimally invasive, or less invasive, techniques has greatly influenced modern cardiac surgery. ${ }^{3,4}$ The variety of operations for which a less invasive approach is technically feasible has been continuously expanded to more complex operations, such as aortic or mitral valve disease, multivessel coronary artery grafting, and even aortic surgery involving the arch. $^{5-7}$ In this issue of JCTVS Techniques, Shah and coworkers $^{8}$ report their institutional experience with a minimally invasive "mini-Bentall" procedure via a partial upper sternotomy and compare mid-term results with those from the conventional full sternotomy approach. In the downloadable narrative video, the authors nicely demonstrate their surgical technique with the miniBentall via an upper hemisternotomy and provide useful hints for preventing surgical complications attributed to the limited access site.

\footnotetext{
From the Department of Cardiac Surgery, Kerckhoff Clinic Bad Nauheim, Campus Kerckhoff, University of Giessen, Giessen, Germany.

Disclosures: The authors reported no conflicts of interest.

The Journal policy requires editors and reviewers to disclose conflicts of interest and to decline handling or reviewing manuscripts for which they may have a conflict of interest. The editors and reviewers of this article have no conflicts of interest.

Received for publication Feb 22, 2021; revisions received Feb 22, 2021; accepted for publication March 1, 2021; available ahead of print March 4, 2021.

Address for reprints: Oliver J. Liakopoulos, MD, Department of Cardiac Surgery, Kerckhoff Clinic Bad Nauheim, Campus Kerckhoff, University of Giessen, Benekestrasse 2-8, 61231 Bad Nauheim, Germany (E-mail: o.liakopoulos@ kerckhoff-klinik.de).

JTCVS Techniques 2021;7:69-70

2666-2507

Copyright (C) 2021 by The American Association for Thoracic Surgery. Published by Elsevier Inc. This is an open access article under the CC BY-NC-ND license (http:// creativecommons.org/licenses/by-nc-nd/4.0/).

https://doi.org/10.1016/j.xjtc.2021.03.003
}

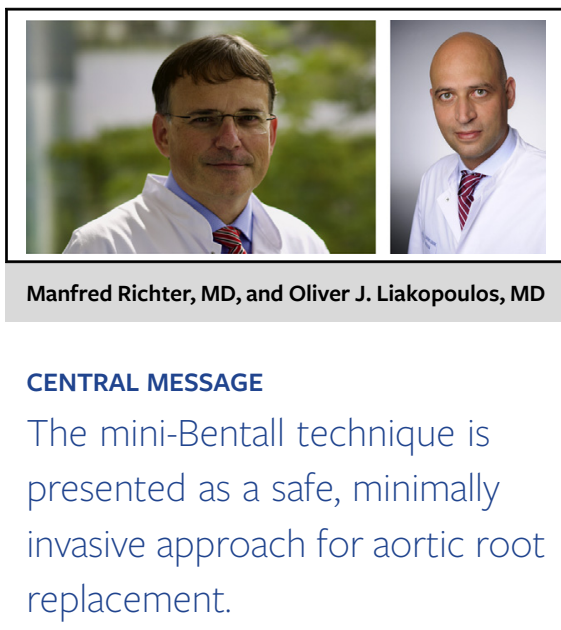

Of note, in the early period, between 2009 and 2014, the Bentall procedure was always performed via a full sternotomy, whereas the mini approach was implemented by the group from 2015 to 2019 . All patients were operated on by a single experienced surgeon, and patient selection was focused on elective patients with indication for first-time aortic-root replacement. Patients requiring redo surgery, repair of the aortic arch or hemiarch, or other concomitant procedures were excluded. These factors certainly limit the generalizability of the approach to a selected patient cohort and demonstrate that the mini-Bentall procedure is technically more demanding. Furthermore, the number of treated patients was relatively small in both groups (mini-Bentall, $\mathrm{n}=48$; full Bentall, ( $\mathrm{n}=49$ ) owing to the single-center design. There were no statistically significant differences between the 2 groups in preoperative patient characteristics or patient outcomes in terms of hard clinical outcome measures for morbidity and mortality. However, patients in the mini-Bentall group had a shorter ventilation time and fewer bleeding complications compared with patients with full sternotomy procedures. Nonetheless, none of the patients with bleeding complications required an exploratory redo thoracotomy, thereby excluding a possible access-related cause.

In summary, Shah and colleagues are to be congratulated for their excellent clinical outcomes independent of the chosen surgical approach. Furthermore, the present report clearly underscores the fact that the increasing demand and patient preference for more minimally invasive techniques in cardiac surgery can be met by meticulous patient selection in experienced centers without reducing safety or surgical efficacy even in more complex cardiovascular pathologies. 


\section{References}

1. Bentall H, De Bono A. A technique for complete replacement of the ascending aorta. Thorax. 1968;23:338-9.

2. Erbel R, Aboyans V, Boileau C, Bossone E, Di Bartolomeo R, Eggebrecht H, et al; ESC Committee for Practice Guidelines. 2014 ESC guidelines on the diagnosis and treatment of aortic diseases: document covering acute and chronic aortic diseases of the thoracic and abdominal aorta of the adult. The task force for the diagnosis and treatment of aortic diseases of the European Society of Cardiology (ESC). Eur Heart J. 2014;35:2873-926.

3. Doenst T, Diab M, Sponholz C, Bauer M, Färber G. The opportunities and limitations of minimally invasive cardiac surgery. Dtsch Arztebl Int. 2017;114:777-84.

4. Mohammed H, Salmasi MY, Caputo M, Angelini GD, Vohra HA. Comparison of outcomes between minimally invasive and median sternotomy for double and triple valve surgery: a meta-analysis. J Card Surg. 2020;35:1209-19.
5. Rayner TA, Harrison S, Rival P, Mahoney DE, Caputo M, Angelini GD, et al. Minimally invasive versus conventional surgery of the ascending aorta and root: a systematic review and meta-analysis. Eur J Cardiothorac Surg. 2020; $57: 8-17$.

6. Wu Y, Jiang W, Li D, Chen L, Ye W, Ren C, et al. Surgery of ascending aorta with complex procedures for aortic dissection through upper ministernotomy versus conventional sternotomy. J Cardiothorac Surg. 2020; 15:57.

7. Risteski P, El-Sayed Ahmad A, Monsefi N, Papadopoulos N, Radacki I, Herrmann E, et al. Minimally invasive aortic arch surgery: early and late outcomes. Int J Surg. 2017;45:113-7.

8. Shah VN, Kilcoyne MF, Buckley M, Sicouri S, Plestis KA. The mini-Bentall approach: comparison with full sternotomy. J Thorac Cardiovasc Surg Tech. 2021;7:59-66. 